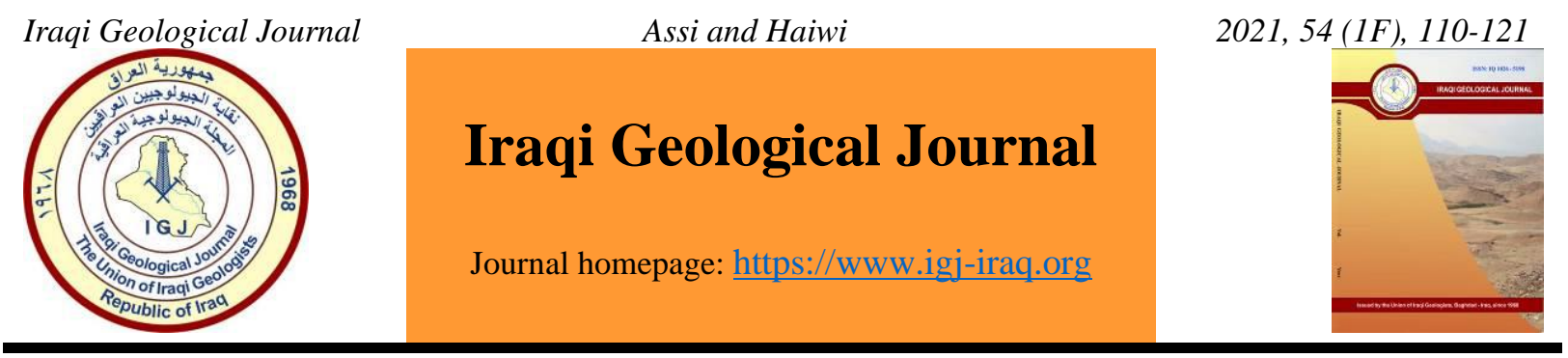

\title{
The Effect of Weighting Materials on the Rheological Properties of Iraqi and Commercial Bentonite in Direct Emulsion
}

\author{
Amel Habeeb Assi ${ }^{1}$ and Ahmed Abdallah Haiwi ${ }^{2, *}$ \\ 1 College of Engineering, University of Baghdad, Baghdad, Iraq \\ 2 Basra Oil Company, Basrah, Iraq \\ * Correspondence:e-mail: ahmed.ah75@yahoo.com
}

Received: 7 February 2021; Accepted: 19 April 2021; Published: 30 June 2021

\begin{abstract}
Numerous drilling additives and materials are used continuously because they are necessary to support and give the required properties of the drilling fluid so that to ensure the stability of the borehole. This paper aspires to evaluate the rheological properties of bentonite (montmorillonite) Trefawey as an alternative to using commercial bentonite. Monitoring and evaluating of the rheological and filtration properties were prepared. This exertion aims to focus on the effect of hematite, and barite on the rheological properties of the three aforementioned bentonite types. An improvement in the rheological properties of bentonite (montmorillonite). Trefawey was observed after adding the previous heavy materials. Hematite has by some means better ability to improve rheological properties compared to other heavy materials. The emulsifying agent used was Carboxyl Methyl Cellulose ( $\mathrm{HOCH}_{2} \mathrm{COONA}$ ), as it has provided excellent results parallel to the lignite. The rheological properties of bentonite (montmorillonite) Trefawey are enhanced by doubling the amount of carboxyl methyl cellulose $\left(\mathrm{HOCH}_{2} \mathrm{COONA}\right)$. The results have proved that the use of weighting materials and emulsifying agent affected the rheological properties of bentonite (montmorillonite) Trefawey in a direct emulsion. The results have shown that it is more appropriate to use carboxyl methyl cellulose as an emulsifying agent to prepare a direct emulsion than bentonite (montmorillonite) Trefawey due to its excellent effect in improving the rheological properties of bentonite (montmorillonite) Trefawey. And it can be said that this effort has succeeded in studying two effects simultaneously. In other words, both heavy substances and emulsifying agent have effects on bentonite (montmorillonite) Trefawey, in order to obtain a stable emulsion and a clearer view of the behavior of Iraqi bentonite. The above effort has focused on making bentonite (montmorillonite) Trefawey suitable for the nature of geological layers such as oil shale, limestone and sandstone. This means preparing drilling fluid using bentonite (montmorillonite) Trefawey to drill the above structures. The study has concluded that it is better to use bentonite (montmorillonite) Trefawey in preparing direct oil emulsions as a stable and successful alternative of imported bentonite.
\end{abstract}

Keywords: Rheological properties; Iraqi bentonite; Weighting material; Emulsion

\section{Introduction}

As mentioned by (Simpson, 1985), one of the most important characteristics that mud should possess is that it has adequate weight or density which enriches the stability of the borehole and prevents bursting, and low viscosity and gel strength which reduce drilling problems. Carboxyl Methyl Cellulose

DOI: $\underline{10.46717 / \mathrm{igj} .54 .1 \mathrm{~F} .10 \mathrm{~ms}-2021-06-30}$ 
(CMC) is one of the most popular emulsifiers, as adding $\mathrm{CMC}\left(\mathrm{HOCH}_{2} \mathrm{COONA}\right)$ increases the viscosity of the mud and decreases filtration, in addition of being an emulsifying agent. The most characteristic feature of drilling mud is its viscosity (Rabia,1985). This is the benefit of emulsions in the petroleum industry and the preparation of drilling fluids in order to improve the viscosity and yield point of the mud used and reduce drilling problems (Menzel,1973).

Several studies have been conducted to investigate the performance of Ca-bentonite in drilling mud in order to activate it by using various additives. Olatunde et al. (2007) researched the activation of a Ca-montmorillonite claystone (composition of Digma) of Wade Bashara in the western desert of Iraq by using tetra odium pyrophosphate as a dispersing agent. They investigated the effect of various factors such as solid slurry concentration, amount of dispersant and mixing times of dispersant / slurry on the efficiency of Iraqi bentonite. Barite is a weighting material widely used for obtaining drilling fluids of high density due to its high density $\left(4.2-4.48 \mathrm{~g} / \mathrm{cm}^{3}\right)$, low cost. It is important to mention that it is considered relatively less harmful to the environment (Ogbeide, and Igbinere, 2016). Suspension of weights is important because the non-suspended particles will not increase the hydrostatic pressure of the drilling mud, and this in turn will create serious problems in well control. (Amel ,2017 a) found that drilling mud have the properties of suspension and filtering control when polymers such as polyacrylamide and xanthan are mixed with bentonite particles. Weighting resources are solid supplies when on hold or melted in water increases the mud density (Balhoff, 2011). Increase in density results in enlarged penetration rate. On the other hand, when the density is unwarranted, it can cause many different sticking pipe (Amel, 2017b). Due to the high demand and the scarcity of barite resources, many research studies have been conducted in order to adopt a heavy-duty material that can be used during well drilling (Abdul Majeed, 2020).

What is new in this study is to find the effectiveness of Iraqi bentonite in direct oil emulsions. As it has been indicated previously, most of the previous studies focused on activating Iraqi bentonite in water-based clays and not emulsifiers as this study does. The aim of this research is to work on the possibility of using Iraqi calcium montmorillonite clay (Ca-bentonite) as one of the available and low-cost mineral resources in Iraq, which was obtained from Wade Bashara, Western Desert, Anbar to be used as a viable alternative of commercial bentonite. This can be considered the first goal. The second objective is to find the effect of heavy substances on Iraqi Bentonite (IB) in direct emulsions and to activate IB using an appropriate emulsifier in order to obtain a stable emulsion.

\section{Materials and Methods}

\subsection{Bentonite}

Since ancient times, humans have used clay externally or internally to maintain a healthy body or treat some diseases. Meanwhile, there are a handful of scientific articles reviewing the beneficial effects of clay on body function. Bentonite clay is a type of clay found in nature, and it is used as traditional customs and remedies in many cultures. In this effort, the bentonite or (montmorillonite) Trefawey claystone used in this study are the samples taken from the Al-Anbar Trfawey location, in the Western Desert of Iraq. Fig.1 indicates the location from which the bentonite is taken. X-Ray Fluorescence (XRF) analysis was performed by XRF Spectrometry via SHIMADZU XRF-1800 at the German laboratory at the University of Baghdad, College of Science. The investigations for Iraqi bentonite and commercial bentonite are shown in Table 1. 


\subsection{Commercial Bentonite}

Calcium Bentonite $(\mathrm{CaB})$ is a type of bentonite used for drilling mud It is white powder and is a natural clay with a fine, soft texture. It is an impure clay composed mainly of montmorillonite. Its boiling point is $381.8^{\circ} \mathrm{C}$ and is imported from China.

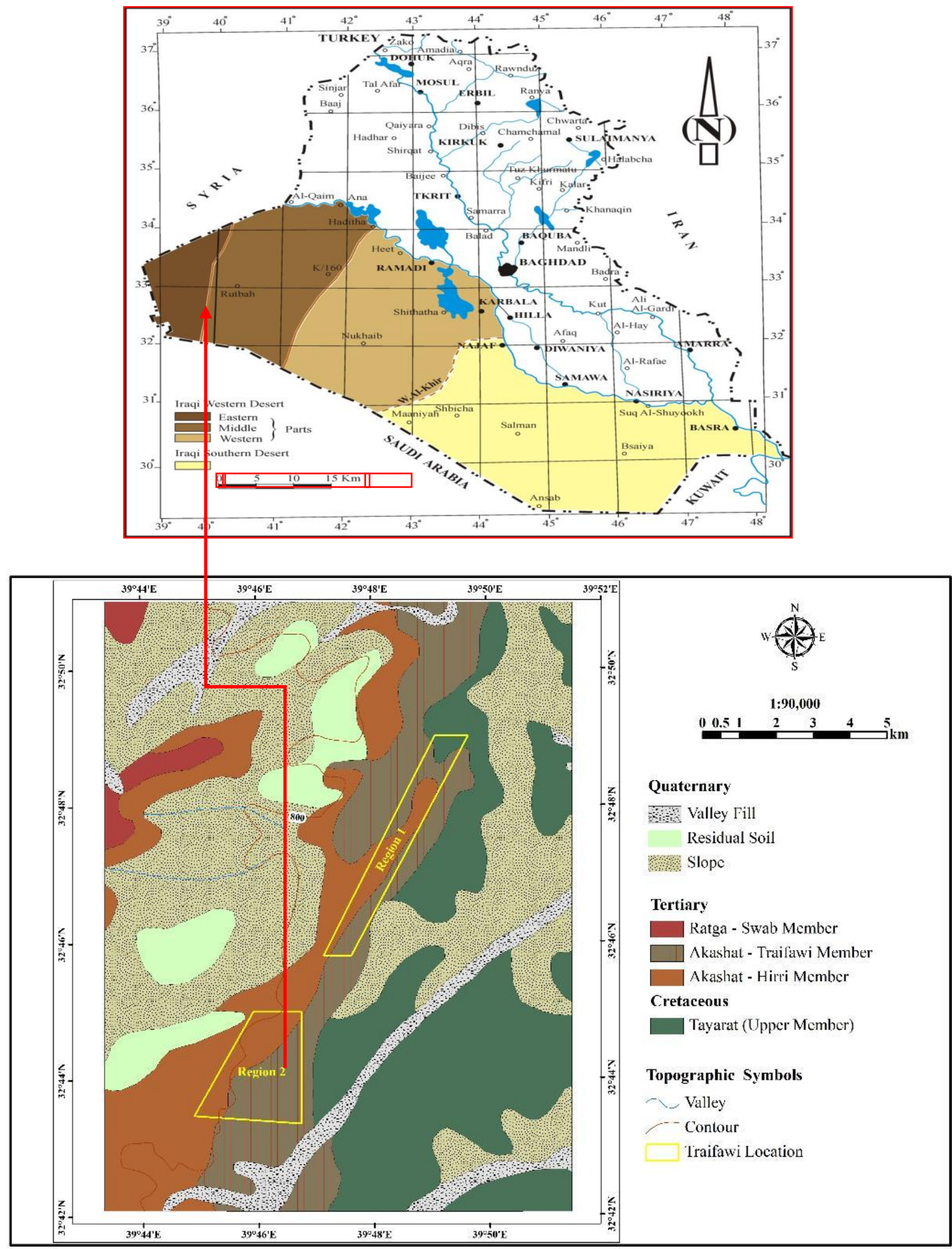

Fig. 1. Trefawey area where bentonite or montmorillonite claystone is Found (GEOSURV, 2021) 


\subsection{Carboxyl Methyl Cellulose (CMC)}

cellulose gum is a cellulose derivative with Carboxyl Methyl Collections (-CH2-COOH) certain to approximately of the hydroxyl collections of the glucopyranose monomers which brand up the cellulose backbone. It is frequently used as sodium CMC. It is used to be advertised in the designation Tylose, a recorded logo of Specific Energy (SE) Tylose (Sissakian et al., 2018)

\subsection{Gas Oil}

is recognized in several terms, but another common sign is red diesel (Dosunmu and Joshua, 2010).

\subsection{Barite}

The extraordinary specific gravity for the barite creates its appropriate for an extensive variety of industrial, medical, and manufacturing usages. Numerous commercial barite mines are harvested from those remaining deposits, it has specific gravity 4.2 to 4.5. Barite frequently occurs like concretions and void-filling crystals at sedimentary rocks (Assi, 2020). It is exclusively public like concretions and vein fillings in limestone. Where those carbonate rock elements have been deeply weathered, huge accumulations of barite are occasionally created through the soil-bedrock contact (Adams and Charrier,1985).

\subsection{Iron Oxide}

Essentially hematite, $\mathrm{Fe}_{2} \mathrm{O}_{3}$. Hematite is used to raise mud density in both water -based and oilbased drilling muds. Iron oxides have a number of disadvantages including: magnetic behavior that effects directional units and magnetic log. It has specific gravity 4.9 to 5.3. (Menzel, 1973) stated that iron oxides can be used like weighting agents in drilling fluid. Iron oxides have greater specific gravity 4.6 to 5.3 that documents slighter quantity of substantial to offer same mud density comparing with barite.

Table 1. XRF analysis for bentonite (montmorillonite) Trefawey and commercial bentonite

\begin{tabular}{ccc}
\hline Component \% & Iraqi Bentonite & $\begin{array}{c}\text { Commercial Bentonite } \\
\text { (China) }\end{array}$ \\
\hline $\mathrm{SiO}_{2}$ & 49 & 62 \\
$\mathrm{TiO}_{2}$ & 0.66 & 0.78 \\
$\mathrm{Al}_{2} \mathrm{O}_{3}$ & 19 & 20.23 \\
$\mathrm{Fe}_{2} \mathrm{O}_{3}$ & 6.55 & 4.2 \\
$\mathrm{MnO}$ & 0.7 & 0.7 \\
$\mathrm{CaO}$ & 2.44 & 1.5 \\
$\mathrm{MgO}$ & 4.33 & 3.8 \\
$\mathrm{Na}_{2} \mathrm{O}_{3}$ & 1.99 & 0.88 \\
$\mathrm{~K}_{2} \mathrm{O}$ & 0.87 & 0.04 \\
$\mathrm{P}_{2} \mathrm{O}_{5}$ & 0.88 & 0.36 \\
$\mathrm{Cl}$ & 0.11 & 0.07 \\
$\mathrm{SO}_{3}$ & 0.88 & 0.39 \\
$\mathrm{L.} \mathrm{O.} \mathrm{I}$ & 12.59 & 5.05 \\
\hline
\end{tabular}

\subsection{Equipment}

The following laboratory equipment was used to perform the laboratory tests:

1- Fann Viscometer Model-35 to measure mud rheological properties. 
2- Mud Balance to measure mud density.

3 - API Filter Tester to measure mud filtration.

4- Weight balance

5- $\mathrm{pH}$ indicator strip to measure $\mathrm{pH}$ of mud (Assi,2020). Note that all measurements were at laboratory temperature 24 Celsius. The laboratory examinations were conducted at the University of Baghdad, College of Engineering, Drilling Laboratory in the Department of Petroleum Engineering.

\subsection{Sampling and Experimental Procedures}

Certain supplies for this study were scored locally as Iraqi bentonite; entirely data created were obtained from laboratory experimentations. The structures of mud tasters were prepared in typical 350 $\mathrm{ml}$ laboratory barrel. This means that every $1 \mathrm{gm}$. of substantial is added to $350 \mathrm{ml}$. of mud and that equals to adding 1 pound of material to 1 barrel of mud. The bentonite tester is set by mixing $11.5 \mathrm{gm}$. of bentonite and 5,10,15, 20, $25 \mathrm{gm}$. of weighting materials (barite, calcite and hematite) into $350 \mathrm{cc}$ of water and (1.5 to 3) gm. of emulsifying agent CMC and $10 \%$ of gas oil. The mixture is stirred for 10 minutes to reach homogeneity. The samples are then put away at room temperature in locked flask for 24 hours. Mud density generally measured by mud balance. A mud balance was calibrated by fresh water must provide a reading of $8.3 \mathrm{lb} . / \mathrm{gal}$. The mud density experiment is conducted by using a mud balance consisting of a dishonorable and a balance arm and cup, lid, knife-edge, rider, level glass, and counterweight. The cup involved to one end for the balance arm and the counterweight is into the opposite ending. Rheological properties measured by using viscometer are usually used to show solids buildup, flocculation or deflocculating of solids, lifting and suspension capabilities, and for calculating hydraulics of muds. The Plastic Viscosity $(\mu p)$ and

apparent viscosity and the yield Point were gained from 600-RPM and 300-RPM dial readings, and as in Eq. 1, 2 and 3 (Bourgoyne et al.,1986)

$$
\begin{gathered}
\mu p=\varnothing 300-\emptyset 600 \\
Y p=\varnothing 300-\mu p \\
\mu a=\varnothing 600 / 2
\end{gathered}
$$

Where:

$\mu \mathrm{p}=$ Plastic viscosity $(\mathrm{cp})$

$600,300 \mathrm{RPM}$ dial reading $=$ Direct reading from viscometer

$\mu \mathrm{a}=$ Apparent viscosity $(\mathrm{cp})$

YP: Yield Point, lb./100ft ${ }^{2}$

The Dead-Weight-Hydraulic Filter Press is used for measuring filter size, and mud cake for the samples is a Series 300 Filter Press armed by a Dead-Weight Hydraulic Assemblage. The process was then frequent for Iraqi bentonite to develop its rheological properties by using $6 \%$ of IB and $3 \mathrm{gm}$ of $\mathrm{CMC}$ and $350 \mathrm{cc}$ of water and $10 \%$ of gas oil. The total numbers of samples are 23 samples of drilling fluid presented in Table 2., which contain the main compounds for the used samples.

\section{Results and Discussion}

Geochemical and mineralogical properties of the bentonite studied are given in Table 1. From Table .1 XRF results, commercial bentonite contains a high percentage of silicon and alumina, and this contributes to giving it higher viscosity values than Iraqi bentonite to some extent. The results of the 
plastic viscosity showed that the addition of the heavier substances increased the viscosity of the direct emulsions with the same effect on the base water bodies and that hematite had a greater effect than the effect of barite. That increasing in the attentiveness of solids may increase the friction among the molecules at the deposited particle, as publicized in Fig. 2. It was determined that hematite ha the largest effect on the yield point compared to the barite. This increasing of yield point is caused by the increase in solid content. It also depends on the particle size of local and commercial bentonite and on the grain size of hematite and barite. Through the results shown in Fig.3, it is noticed that hematite had the largest influence on the value of the yield point, especially at an addition ratio of $10 \mathrm{~g}$ and above. This is due to the chemical nature of hematite, the speed of its interaction with bentonite and the nature of its charges. Also, it has the ability to interact quickly and to attract and repulse against each other. This makes it the most influential on the yield point.

Table 2. Direct emulsion formulation used in this study

\begin{tabular}{lccc}
\hline Component & Amount & Unit & Function \\
\hline Water & 350 & $\mathrm{ml}$. & Base fluid \\
$\begin{array}{l}\text { Bentonite (Iraqi and } \\
\text { commercial) }\end{array}$ & 11.5 & $\mathrm{gm}$. & Viscosity control \\
CMC & 1.5 to 3 & $\mathrm{gm}$. & Emulsifying agent \\
Gas oil & 35 & $\mathrm{ml}$. & Increase lubricating \\
Barite & 5 to 25 & $\mathrm{gm}$. & Weighting material \\
Hematite & 5 to 25 & $\mathrm{gm}$. & Weighting material \\
\hline
\end{tabular}

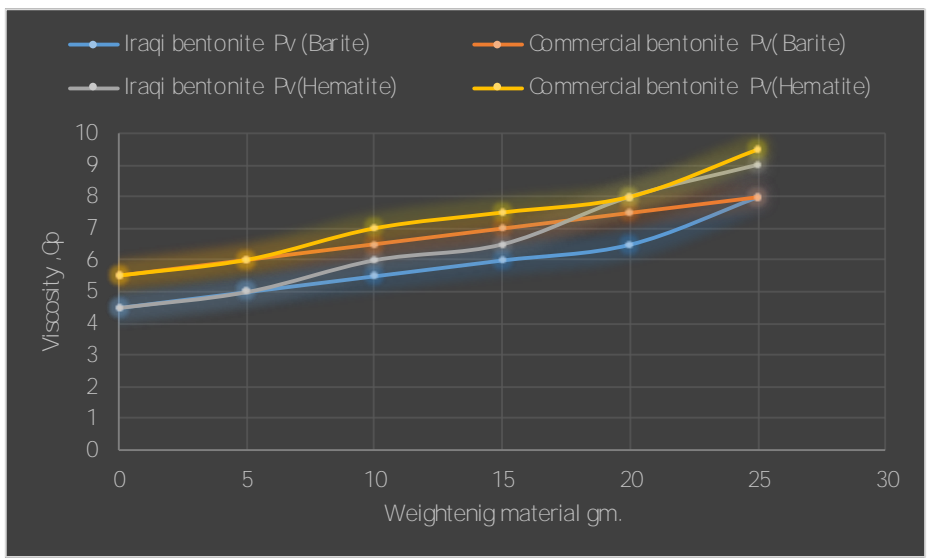

Fig. 2. The effect of heavy materials on the viscosity of Iraqi and commercial bentonite

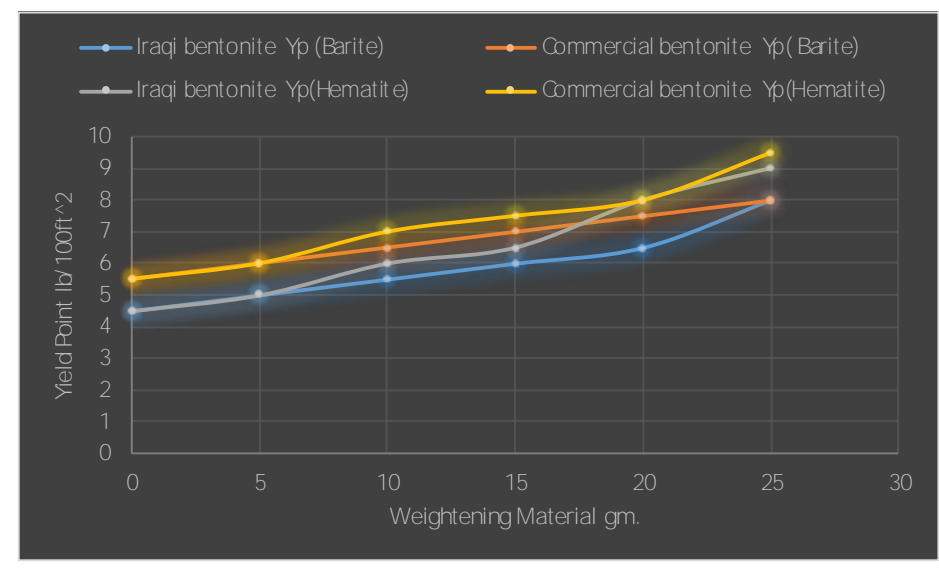

Fig. 3. The effect of heavy materials on the yield point of Iraqi and commercial bentonite 
To evaluate the effect of the weight of the clay of barite and hematite on the Iraqi and imported bentonite, the results indicate that the same weight of hematite provides a higher weight of the clay compared to the barite. This is due to the specific gravity of hematite, which is $4.9-5.2 \mathrm{~g} / \mathrm{cm} 3$ presented in detailed in Table 3 to 6 . Filtration tests for commercial bentonite and Iraqi bentonite before and after adding barite and hematite show that the filter volume decreases after adding weighting materials and the thickness of the filter cake increases with the increase in the solid concentration as exposed in Fig. 4, and then this becomes stable. As shown in Table 3 to 6. Hematite is the best effect on the size of the filtrate, as it gave a lower and close filtration rate in both types of bentonite used (Iraqi and commercial). Barite has the greatest effect on the $\mathrm{pH}$ of both samples of bentonite used in this study, as it gave higher $\mathrm{pH}$ values than when adding hematite though it is still within the optimal $\mathrm{pH}$ values, which range between (8.5-11). Generally, improving the $\mathrm{pH}$ of the oil-based drilling fluid based on bentonite in the range 8.5 to 11 will improve the drilling process and reduce the total cost.The reason is that barium hydroxide is a strong base and to the fact that the iron hydroxide of weak bases is soluble by water.The gel strength of the drilling fluid is a measure of the shear stress necessary to initiate a limited shear rate. The gel strength shows that commercial bentonite has a higher gel strength than Iraqi bentonite. After adding hematite, both clays show high gel resistance values. Therefore, hematite additions gave the highest increase in values compared to parite. This increase is due to the presence of ions in hematite. However, if the ions are excessive, they may cause flocculation through a complex attractive, repulsive electrical balance that disappeared in the water. The results also showed that the Iraqi and commercial bentonite solution after a period of time (after adding different concentrations of barite and hematite) always becomes less stable and according to this thixotropic property. For Iraqi and commercial bentonite, it will decrease over time, as displayed in Table 3. to Table 6 .

Table 3. The effect of adding barite on the properties of Iraqi bentonite

\begin{tabular}{ccccc}
\hline Barite gm & Density lb./gal. & Filtration ml. at 30 min & $\mathbf{p H}$ & $\mathbf{1 0}$ min gel strength lb./100sqft \\
\hline 0 & 8.5 & 10 & 9.1 & 6 \\
5 & 8.55 & 9.75 & 9.34 & 6.2 \\
10 & 8.6 & 9.43 & 9.43 & 6 \\
15 & 8.66 & 9.12 & 9.75 & 5.5 \\
20 & 8.87 & 8.89 & 9.85 & 4 \\
25 & 9.1 & 8.72 & 9.99 & 3 \\
\hline
\end{tabular}

Table 4. The effect of adding barite on the properties of commercial bentonite

\begin{tabular}{ccccc}
\hline Barite gm & Density lb./gal. & Filtration ml. at 30 min & $\mathbf{p H}$ & $\mathbf{1 0}$ min gel strength lb./100sqft \\
\hline 0 & 8.6 & 8.97 & 9.11 & 6.22 \\
5 & 8.65 & 8.75 & 9.2 & 6.2 \\
10 & 8.7 & 8.53 & 9.27 & 6 \\
15 & 8.78 & 8.44 & 9.38 & 5 \\
20 & 8.97 & 8.39 & 9.46 & 4 \\
25 & 9.17 & 8.22 & 9.52 & 4.5 \\
\hline
\end{tabular}

Table 5. The effect of adding Hematite on the properties of Iraqi bentonite

\begin{tabular}{ccccc}
\hline Hematite gm & Density lb./gal. & Filtration ml. at 30 $\mathbf{~ m i n}$ & $\mathbf{p H}$ & $\mathbf{1 0}$ min gel strength lb/100sqft \\
\hline 0 & 8.5 & 10 & 9.1 & 6 \\
5 & 8.65 & 9.2 & 9.1 & 6.5 \\
10 & 8.7 & 9.01 & 9.11 & 6.6 \\
15 & 8.86 & 8.88 & 9.15 & 5.99 \\
$\mathbf{2 0}$ & 8.9 & 8.7 & 9.18 & 4.5 \\
$\mathbf{2 5}$ & 9.35 & 8.65 & 9.2 & 4 \\
\hline
\end{tabular}


Table 6. The effect of adding Hematite on the properties of commercial bentonite

\begin{tabular}{ccccc}
\hline Hematite gm & Density lb./gal. & Filtration ml. at 30 min & $\mathbf{p H}$ & $\mathbf{1 0}$ min gel strength lb./100sqft \\
\hline 0 & 8.5 & 10 & 9.1 & 6 \\
5 & 8.65 & 9.2 & 9.12 & 6.5 \\
10 & 8.7 & 9.01 & 9.13 & 6.7 \\
15 & 8.86 & 8.88 & 9.15 & 5.99 \\
20 & 8.9 & 8.7 & 9.18 & 5 \\
25 & 9.35 & 8.65 & 9.18 & 4.5 \\
\hline
\end{tabular}
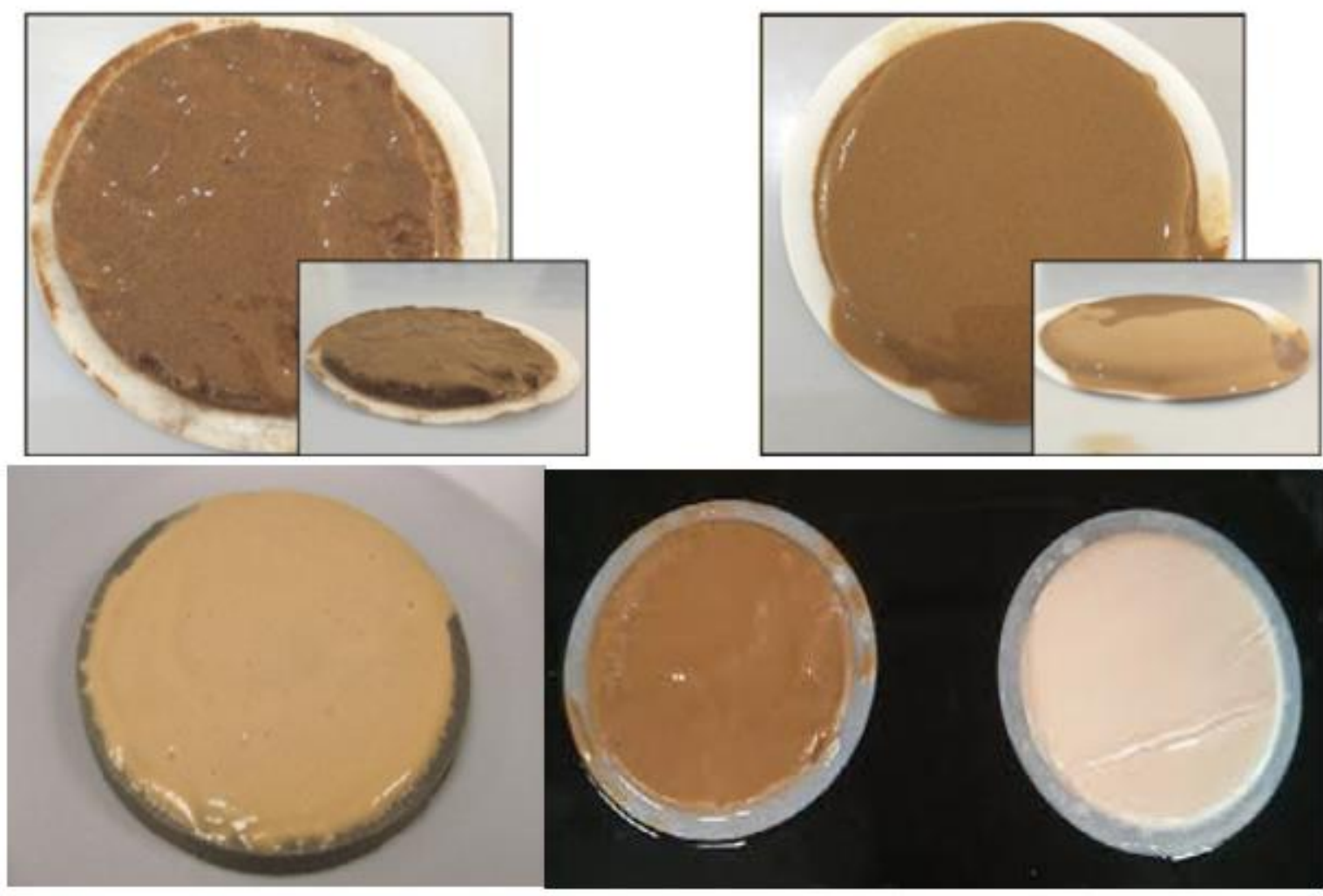

Fig. 4. The effect of heavy materials on the mud cake of Iraqi and commercial bentonite

In order to form an emulsion, there must be two liquids that do not mix with one another, the presence of emulsifying agents and the mixing period sufficient for the propagation of the discontinuous phase in the continuous phase. In the oil industry, oil and water are two liquids that do not mix with one another except in the presence of an emulsifying agent. Perhaps it is very important when thinking about the stability of the emulsion, to realize that the mixture formed from pure oil or pure water without the presence of an emulsifying agent and the absence of mixing, will lead to the formation of an easy-to-separate emulsion that can be easily separated, since the nature of mixed liquids is to obtain the lowest possible contact or the least possible surface area. Therefore, the water will disperse in the form of spherical droplets, and the small droplets will tend to merge with each other to form larger drops, and in the absence of an emulsifying agent, these drops will settle at the bottom, forming a small surface area. As for emulsifiers, they are surface active substances that have a tendency to dissolve in one of the two liquid phases, which leads to an increase in the separation limit concentration. There are many ways in which the emulsifying agent changes the quality of diffusion in the emulsion as shown in Fig. 5. It is necessary to refer to the important and the effective role of the emulsifying agent used in this study, 
which is CMC. The amount of emulsifying agent was doubled twice to $3 \mathrm{gm}$, and added to the samples of Iraqi bentonite, which contains hematite as a heavy substance due to its efficiency. Fig. 6 shows the effect of adding CMC on Iraqi bentonite, and it is clear that the performance of Iraqi bentonite improved greatly after increasing the amount of emulsifying agent and gave values of viscosity much higher than imported bentonite. Fig. 7 presents the effect of increasing the CMC value on the yield point value of Iraqi bentonite, and the significant improvement is very clear in that property after increasing the amount of $\mathrm{CMC}$ added. Fig. 8 displays the effect of increasing the $\mathrm{CMC}$ value on the filter volume value of Iraqi bentonite, and the great improvement is very clear in that characteristic after increasing the amount of added CMC, as the filtrate volume decreased significantly and gave significantly better performance than imported bentonite.

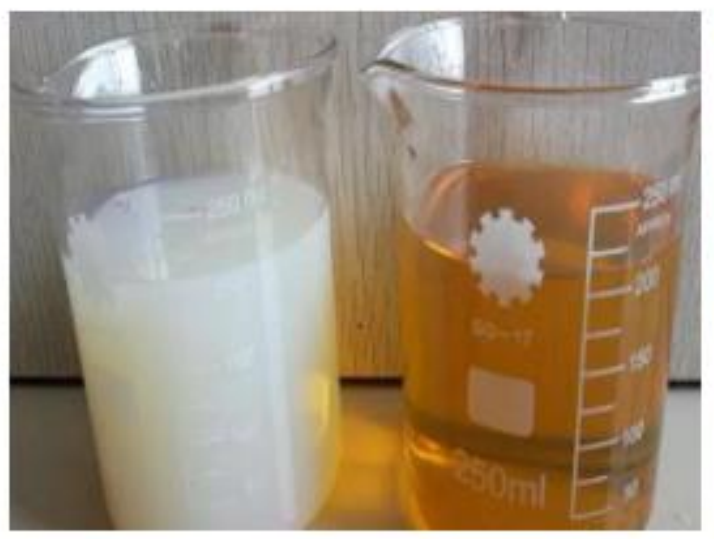

a

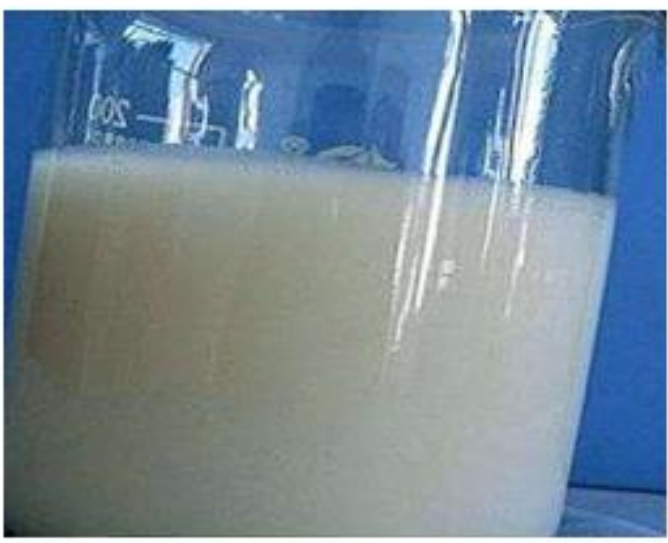

b

Fig. 5. (a). Gas oil and emulsifying agent CMC solution (b) emulsion after mixing gas oil and CMC solution and Iraqi bentonite

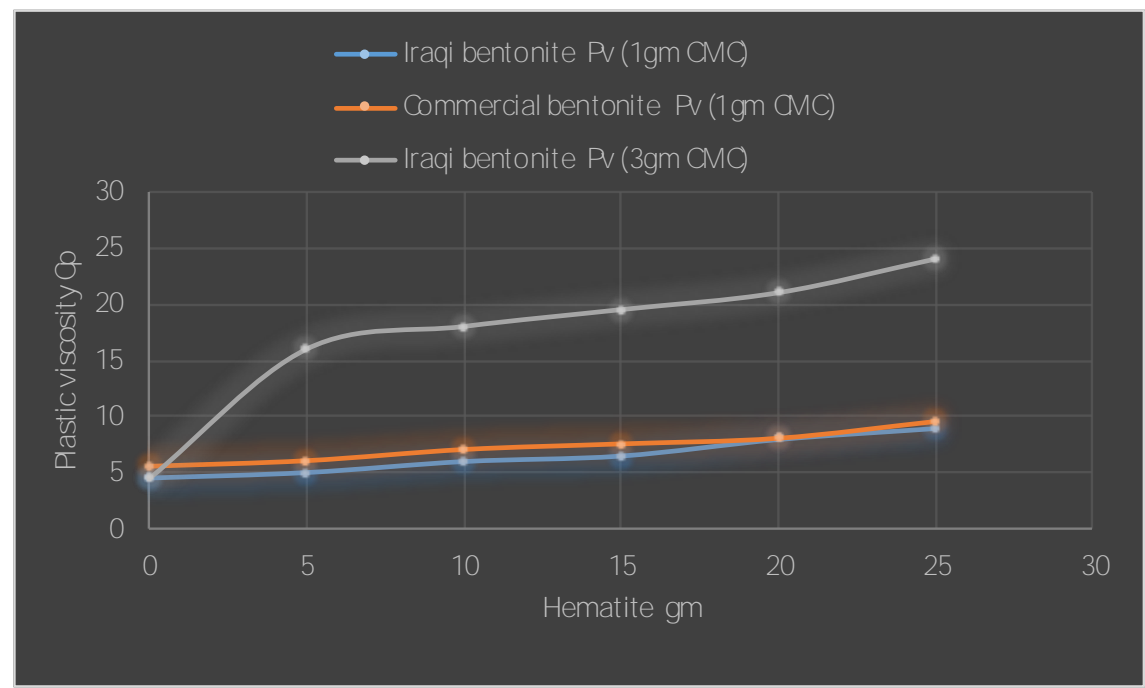

Fig. 6. Effect of CMC addition on the plastic viscosity of Iraqi bentonite 


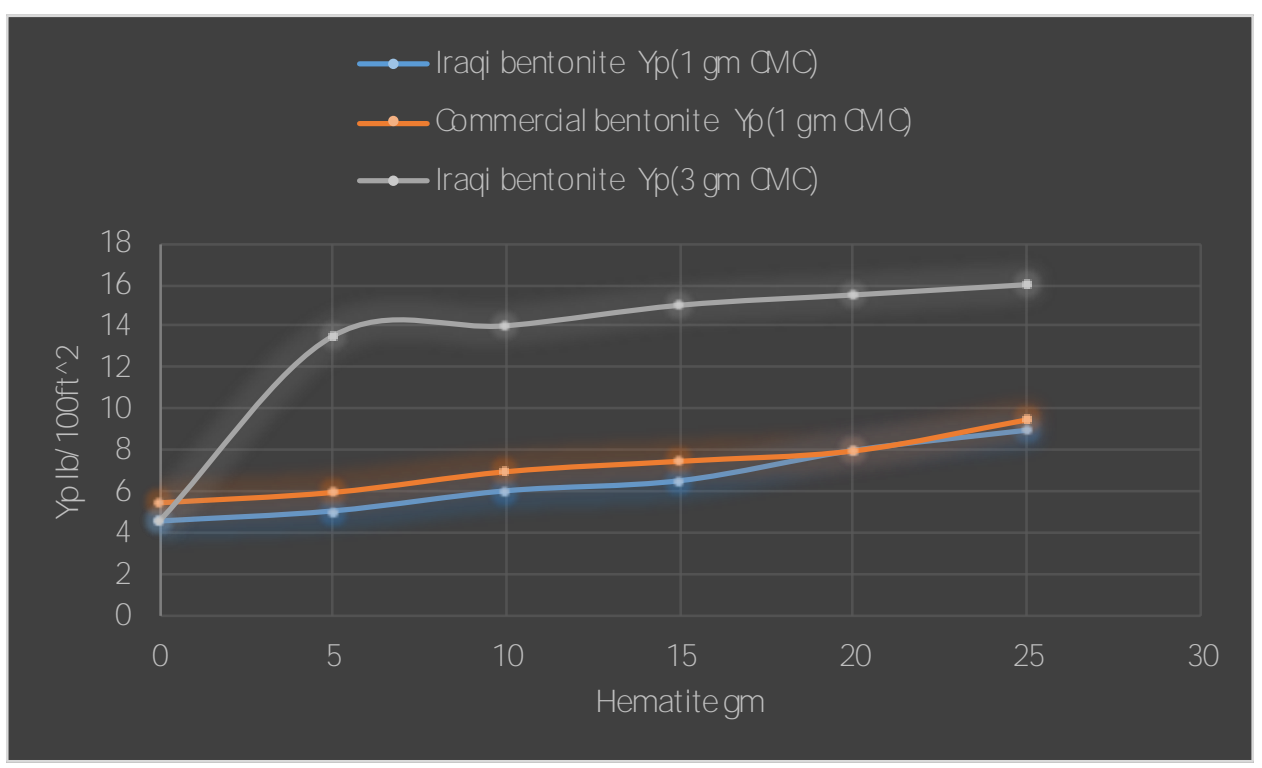

Fig. 7. Effect of CMC addition on the yield point of Iraqi bentonite

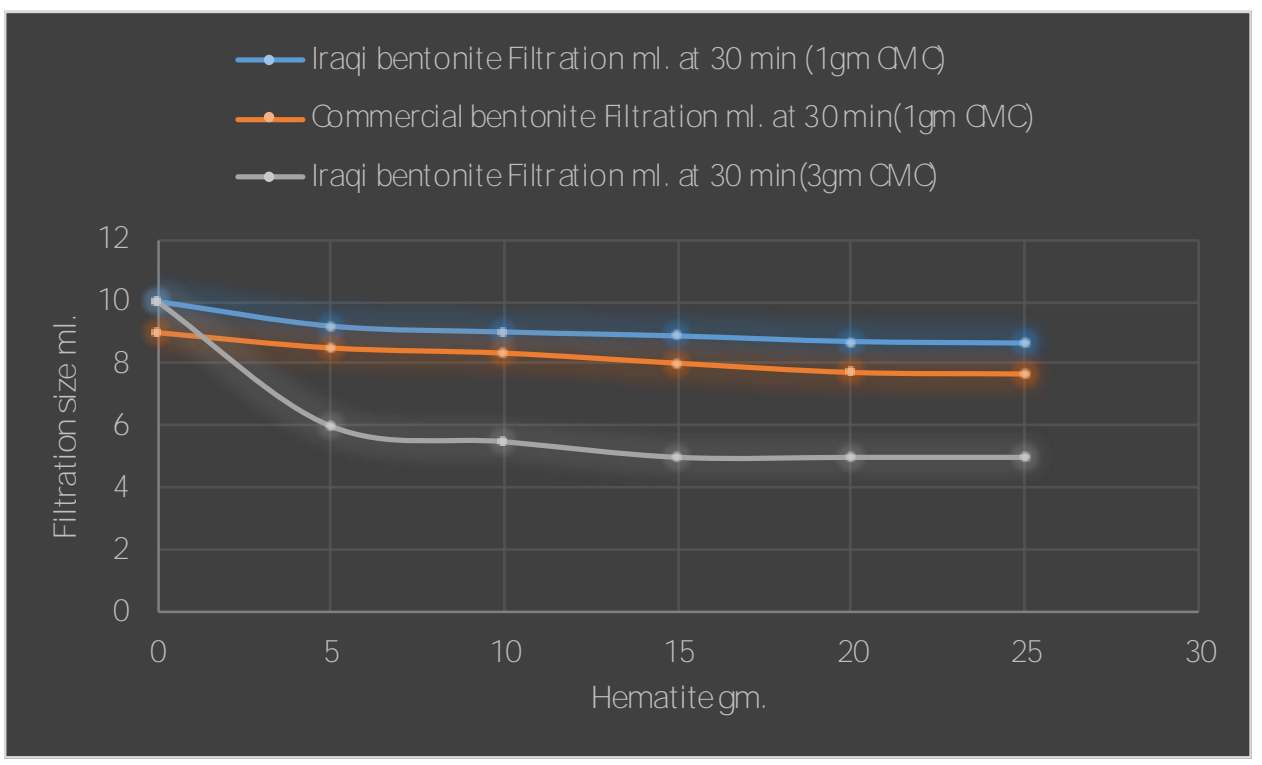

Fig. 8. Effect of CMC addition on the filtration size of Iraqi bentonite

Particle Size Spreading D50 is also recognized by way of median diameter or medium rate of particle size sharing. It is the assessment of the atom diameter at $50 \%$ in the accumulative distribution. Particle Size Spreading D50 is unique and a significant limit describing particle size. For instance, if $\mathrm{D} 50=5.8 \mu \mathrm{m}$, at that point $50 \%$ of the particles in the taster are greater than $5.8 \mu \mathrm{m}$, and $50 \%$ lesser than $5.8 \mu \mathrm{m}$. D50 is typically used for representing the particle size of collection. Fig. 9 illustrates the D50 for the materials used. It's clear that all the used materials have D50 less than Iraqi bentonite except barite and CMC. Indeed, this is considered one of the important points to prove the effectiveness of the material used, as it is preferable that the material with D50 be less than bentonite to increase the effectiveness of mixing and reduce solid segregation and sedimentation. In other words, is to obtain a homogeneous and effective mixture. 


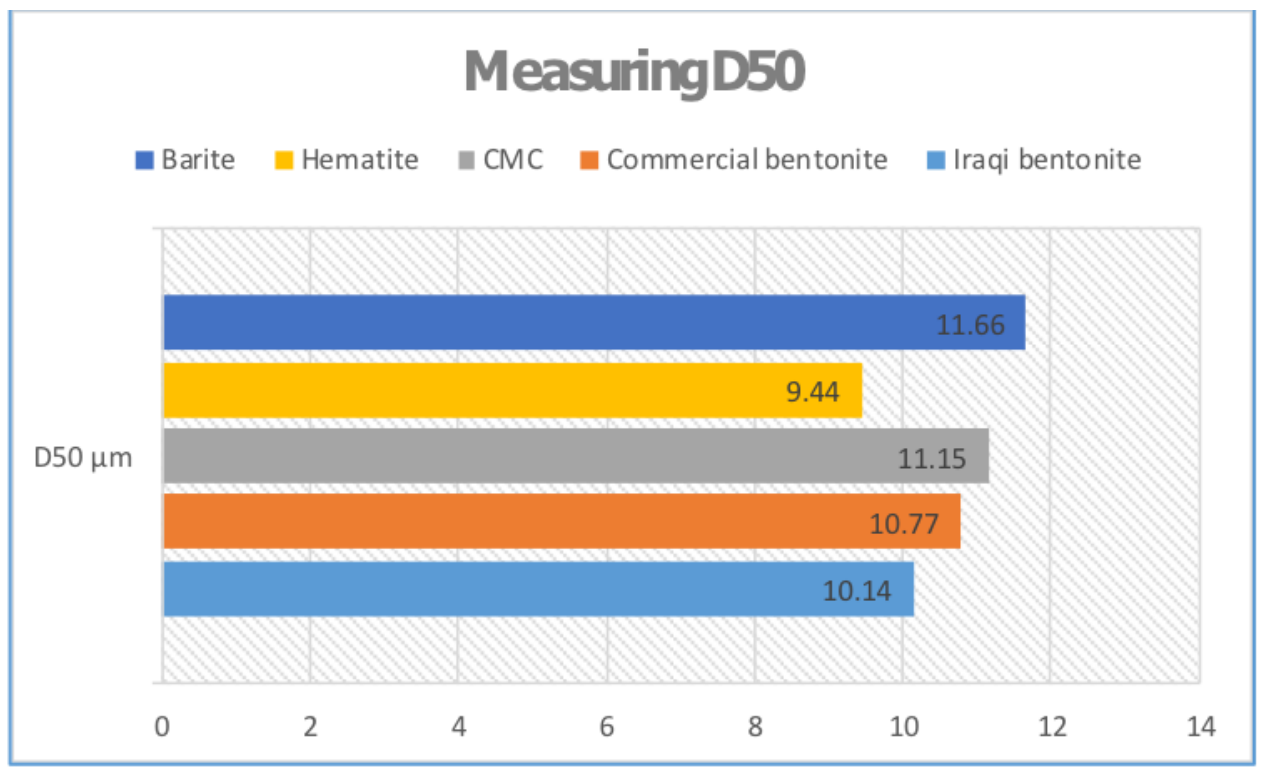

Fig. 9. The D50 for the used materials

\section{Conclusions}

This study dealt with investigating the effect of weighting materials on drilling fluid rheological properties. This study had two objectives. The first is to find the effect of the heavy materials on the rheological properties of bentonite, whether Iraqi or local, in direct emulsions. The second objective is closely related to the first: finding the effectiveness of the overburden materials in improving the performance of the Iraqi bentonite. The results of this research on comparing the performance of Iraqi and imported bentonite in oil emulsifiers showed that it is possible to use Iraqi bentonite as a successful alternative of imported bentonite, but by doubling the amount of CMC emulsifying agent three times. This study has proved that hematite is the best performance with oil emulsions and has contributed well to improving the rheological and filtration properties of Iraqi bentonite. Hematite has little moisture, consequently using this over other weighting resources may guarantee fewer hydration. Paralleled to barite, hematite has benefits for instance higher specific gravity, better solubility in acidic area and a subordinate rate of depletion in over-all - the latter in line for its hardness. And by making a simple comparison between the addition of $0 \mathrm{~g}$ and $20 \mathrm{~g}$ of hematite, it was noticed that the effect was an increase of $50 \%$, that is, a double for the rheological properties, and by conducting the same method above, the increase was by $35 \%$ for the barite. As for the $\mathrm{pH}$, there was an increase of $10 \%$ when adding $20 \mathrm{~g}$ of hematite. As for the barite, it showed a decrease of 5. An important advantage of hematite over barite, regardless of its abundant nature, is that it has a specific gravity higher than 4.9 to $5.3 \mathrm{~g} / \mathrm{cm} 3$. For this reason, drilling companies can use less hematite in the preparation of heavy clays, and achieve the same results compared to barite. Therefore, the cost of the clay is quite low. Hematite is well loaded during drilling applications because it has high purity and is free from contaminants such as mining. Finally, it can be said that both weighting materials and emulsifying agent enhance the performance of Iraqi bentonite in direct emulsion.

\section{Acknowledgements}

It is with great pleasure that I extend my sincere thanks and appreciation to my teacher, Mrs. Media Nuri, for her revision of the research linguistically. The authors are very grateful to the Editor in Chief Prof. Dr. Salih M. Awadh, the Secretary of Journal Mr. Samir R. Hijab, and the Technical Editors for their great efforts and valuable comments. 


\section{References}

Assi, A. H., 2020. The effect of some materials on funnel viscosity reading in water base mud. Iraqi Geological Journal, 53(1E), 32-43.

Abdul Majid, R. K., AL Haleem, A. A., 2020. Estimation of shear wave velocity from wireline logs data for Amara oilfield, Mishrif Formation, southern Iraq, Iraqi Geological Journal, 53(1A), 36-47.

Akpaboi, J. U., 2012. Effect of drilling fluid density on ROP, International Journal of Scientific Innovation, $33(13), 12-23$.

Amel H. A., 2017. Enhancing the lifting capacity of drilling fluids in vertical oil wells, Iraqi Journal of Chemical and Petroleum Engineering, 18 (3).

Amel, H.A., R. Ykoob, 2017. Studying the effects of different polymers on rheological properties of water base muds, Journal of Engineering Number, 10 (23), 22-33.

Adams, N. J., Charrier, T. ,1985. Drilling engineering: A complete well planning approach. (T. Charrier, Ed.). Oklahoma: Penn Well Publishing Company Tulsa, Oklahoma, 13(15), 52-63.

Balhoff, M. T., Lake, L. W., Bommer, P. M., Lewis, R. E., Weber, M. J., Calderin, J. M. 2011. Rheological and yield stress measurements of non-Newtonian fluids using a Marsh Funnel. Journal of petroleum Science and Engineering, 77(3-4), 393-402.

Bourgoyne, A.T. Jr., Millheim, K. K., Chenevert, M. E., Young, F. S., 1986. Applied Drilling Engineering, Society of Petroleum Engineers Text Book Series, Vol.1, Richardson, TX.

Dosunmu, A., Joshua, O. ,2010. Development of environmentally friendly oil-based mud using Palm oil and groundnut-oil. In 34th Annual SPE International Conference and Exhibition (pp. 1-9). Caliber: Society of Petroleum Engineers.

Iraqi Geological Survey (GEOSURV), Department of Informatics, 2021.

Menzel, D.1973, Anew weighting material for drilling fluids based on synthetic iron oxide, Paper SPE 4517-MS, SPE Conference paper, 23(13), 22-37.

Ogbeide, P. O., Igbinere, S. A., 2016. The effect of additives on rheological properties of drilling fluid in highly deviated wells. Futo Journal Series, 2(2), 68-82.

Olatunde, A. O., Usman, O. A., Olafadehan, O. A., Adeosun, T.A., Ufot, O. E., 2007. Improvement of rheological properties of drilling fluid using locally based materials. Petroleum \& Coal, 54(1), 65-75.

Rabia, H. 1985, Study on the Activation of Qara Tappah Iraqi Bentonite and Its Test as Gelling Agent. Al-Mustansiriyah Journal of Science, 22(6), 123-128

Simpson, J. P, 1985, The Drilling mud dilemma-recent examples, SPE 139278-PA Journal of Petroleum Technology, 63(10): 42-53. 